\title{
インレットの安定な湖口断面積に関する研究 CROSS SECTIONAL AREA OF NATURAL AND STABILIZED TIDAL INLET
}

\author{
西隆一郎 1 ・又野友之輔 2 - 山城 徹 ${ }^{3}$ ・日高正康 $4 \cdot$ \\ 林健太郎 5 - Tommy Jansen 6 \\ Ryuichiro NISHI, Tomonosuke MATANO, Toru YAMASHIRO, Masayasu HIDAKA, \\ Kentaro HAYASHI and Tommy JANSEN \\ 1正会員 工博 鹿児島大学教授 水産学部水産学科（广890-0056 鹿児島市下荒田4丁目50-20) \\ 2 工修 株式会社不動テトラ（元）社員（テ103-0016 東京都中央区日本橋小網町7番2号5） \\ 3正会員 工博 鹿児島大学教授 工学部海洋土木工学科（下890-0065 鹿児島市郡元1丁目21-40) \\ 4鹿児島大学講師 水産学部水産学科（广890-0056 鹿児島市下荒田4丁目50-20） \\ 5正会員 工修 (株)アルファ水エコンサルタンツ東京本部（广101-0031 東京都千代田区東神田2-7-9）

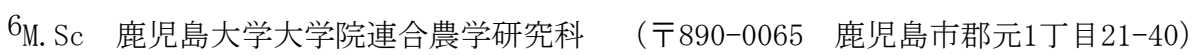

\begin{abstract}
There are a number of natural and artificially stabilized inlets in the world. Natural inlets maybe cut by natural forces such as a flooding of melting snow water, tsunami, and etc., then some of them naturally close and the rest of them keep an inlet mouth open. In addition, many inlets stabilized by single groin and double groins exist. These inlets are important geomorphological features as navigation channels and exchanging inner and outer water. Here, tidal prism data $(P)$ and cross sectional area $(A)$ of inlet in Japan, China, U.S.A., New Zealand, Vietnam, and India are applied to study stability condition of natural and artificial inlets. Derived global A-P equation gives an overestimation (underestimation) of cross sectional area (A) of artificially stabilized inlets when tidal prism $(\mathrm{P})$ is larger (smaller) than $2.383 \times 10^{7}\left(\mathrm{~m}^{3}\right)$. In addition, temporal change in A-P relation at Lake Hamana is examined.
\end{abstract}

Key Words : Inlet, tidal prism, cross sectional area, local A-P relationship, global A-P relationship, inlet review

\section{1. まえがき}

インレットは感潮狭口と呼ばれる沿岸域の地形 である(図-1)。わが国の代表的なインレットとして は，浜名湖やサロマ湖がある。これらのインレット は，外海側からの波や場合によっては津波の作用， あるいは内海側の内水量増加（例えば，雪解け水な ど）により，外海と内海を分断する砂嘴や砂州の一 部が切断された結果形成される場合が多い. 外洋に 面しかつ砂質材料で形成された一般的なインレット では，潮汐に伴う海水の流入・流出が可能であるた め, 潮汐に伴う流れおよび底質移動と, 入射波浪に 伴う沿岸流と底質移動（沿岸漂砂）の相互作用で常 に変形している.

具体的には沿岸漂砂で輸送されてきた砂が上げ 潮・下げ潮により, インレット内部に運ばれて堆積 するとFlood tidal shoal(上げ潮砂州)が形成され， 逆に外洋側に運ばれ堆積するとEbb tidal shoal(下 げ潮砂州) が形成される。そして, 潮流に伴う底質
輸送と波浪に伴う沿岸漂砂のバランスが崩れるとイ ンレットの閉塞を引き起こす場合がある。インレッ 卜は，自然に形成されるだけでなく，人工的に砂州 を開削し作られ，その後，内水面側を漁場として使 用したり，インレット部分を航路としても利用する ので, 安定なインレットを確保・維持することが望 まれる。また，インレットの水路確保を目的に導流 堤などの人工構造物を設置した場合には，インレッ 卜を迂回する沿岸漂砂が人工構造物で阻止されるた めに, 漂砂のバイパスなどを行わなければ, 沿岸漂 砂下手側での海浜侵食の原因ともなることが知られ ており，例えば，わが国の道東沿岸のサロマ湖，能 取湖, 遠州灘海岸の浜名湖などでもインレットでの 航路確保目的の導流堤設置による海浜侵食が問題と なっている.

本論文では，インレットを適切に維持・利用する ためには，インレットの安定な断面形状に関する定 式化が必要と考え, 世界中のどこでも第一近似とし て利用できる汎用 $A-P$ 式 (タイダルプリズムと感潮 
狭口断面積（流積）の関係）について考察する. 次 いで，人工化したインレットが増加し，海岸管理上 の問題ともなっているので, インレットを人工化し た場合のし，A-P 関係（タイダルプリズムと感潮狭 口断面積（流積）の関係）について考察することに した．なお，インレットの変形に関する数值計算も 行っているが, 紙面の関係で, 別途, 述べさせてい ただくことにする.

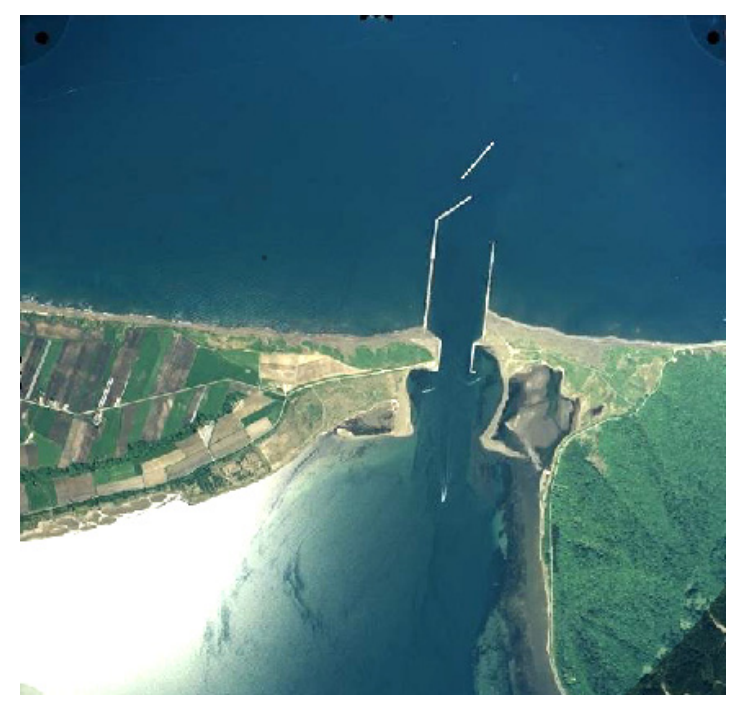

図-1 北海道網走沿岸の能取湖 (海洋情報部提供写真)

\section{2. 汎用 $A-P$ 式（タイダルプリズムとイン レット断面積（流積）の関係）の誘導}

インレットを通して海跡湖内に流入する海水の量, あるいは, 流出する海水の量は, タイダルプリズム $P$ で基本的に評価できる. タイダルプリズムの求め 方には，大別して2通りの方法がある。それらは，

（i）物理的手法；インレットでの流速と水路断面 積（流積）を掛けて時間流量を求め, その時間流量 を下げ潮あるいは上げ潮の間で時間積分する方法,

（ii）幾何学的手法; 内水面（海跡湖）の面積に潮 位差を掛ける方法である。世界の各地で実際のイン レットを対象にタイダルプリズムを求める場合には, 計算精度を気にしなければ, 後者の手法が当然なが ら算定しや寸い。 そこで, 本論文中のデータ解析で は主に後者の手法を採用する。しかし後者の手法で タイダルプリズムPを算定すると、インレットにお ける複雑な潮流と底質移動の物理現象が, 何故、単 純な $A-P$ 関係式で表現できるのか理解しにくい。 そ こで，インレットを通過する時間流量の積分からタ イダルプリズムを求める物理的な手法に基づいて $A-$ P関係式の誘導を行うことにする.

（1）物理的手法（時間流量積分型）によるタイダル プリズムの誘導

海跡湖内におけるインレット（湖口）を通しての 海水交換量（タイダルプリズム $P$ ) が，湖口の断面
積 $A$ と何故簡単な $A-P$ 関係式で表されるのかという 疑問がある. そこで, 海跡湖内での海水交換量を, 湖口における瞬間流量（瞬間速度 $\times$ 瞬間断面積）の 1 潮汐間内での時間積分により求めることで, $A-P$ 関係式が，理論的にも正しいことを誘導する.

なお，誘導に当たっては，（ケース1）外洋域型 (湖口の水位 $h(t)$ と水平流速 $u\left(t_{0}\right)$ の位相が $90^{\circ}$ 異な る場合の 1 潮汐間内での海水交換量), (ケース 2$)$ 同位相型（湖口の水位 $h(t)$ と水平流速 $u\left(t_{0}\right)$ の位相が 同位相の場合の 1 潮汐間内での海水交換量 $), \quad($ ケー ス3）一般型（湖口の水位 $h(t)$ と水平流速 $u\left(t_{0}\right)$ の位 相差が $\varphi^{\circ}$ の場合の 1 潮汐間内での海水交換量) の 3 夕 イプに分け，ケース 1 と2については関係式を，ケー ス3のみ式の誘導を示す。ここで， tは水位の任意の 時間, $t_{0}$ は水平流速の時間を示す.

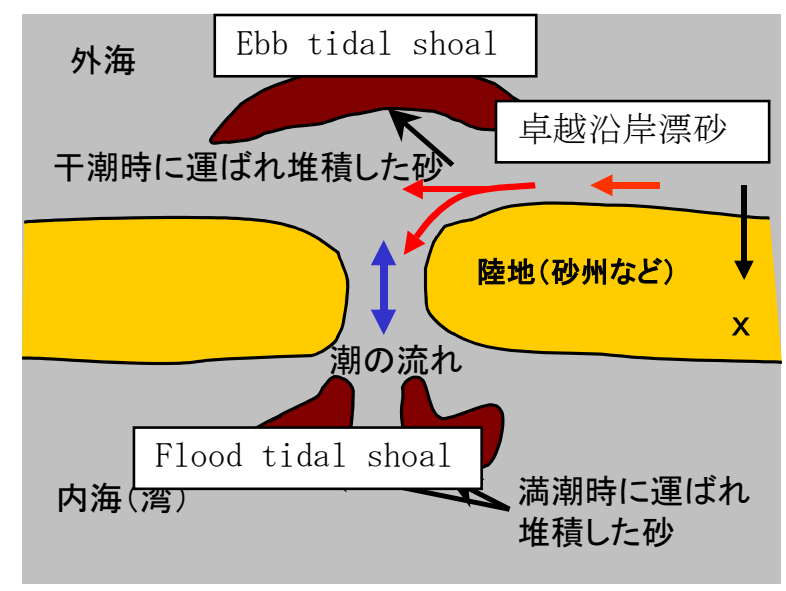

図-2 インレット(感潮狭ロ)の流れと底質移動の模式図

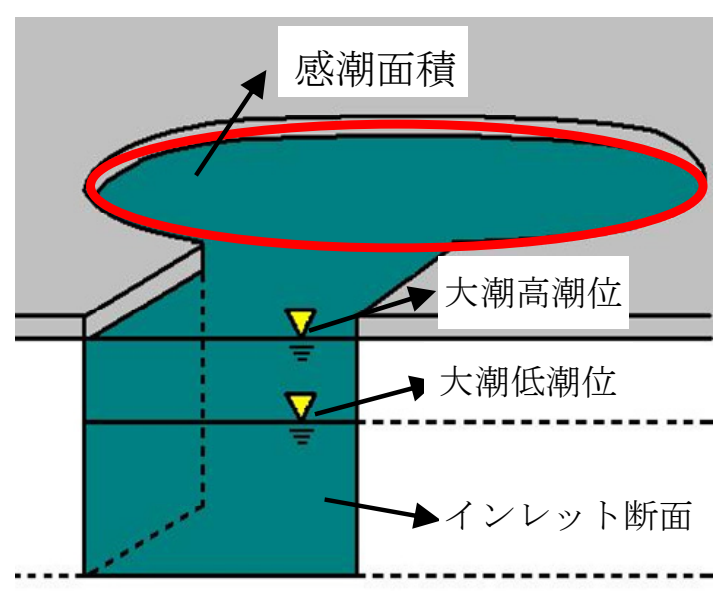

図-3 A(インレット断面積) $P($ タイダルプリズム) の模式図 
ヶース 1; 外洋域型（湖口の水位 $h(t)$ と水平流速 $u\left(t_{0}\right)$ の位相が $90^{\circ}$ 異なる場合の潮汐による海水交 換量)

一日1回潮と一日2回潮に対して $A-P(D)$ 関係式は それぞれ，次式で示すようになる；

（i）一日1回潮の場合は;

$$
\begin{aligned}
& D=27516 A_{e} \\
& A_{e}=3.3634 \times 10^{-5} \mathrm{P}
\end{aligned}
$$

（ii）一日2回潮の場合は;

$$
\begin{aligned}
& D=13758 A_{e} \\
& A_{e}=0.7268 \times 10^{-5} P
\end{aligned}
$$

ここで，Dは海水交換量（放出量）を示す.

\section{ヶース 2; 同位相型（湖口の水位 $h(t)$ と水平流速} $u\left(t_{0}\right)$ の位相が同位相の場合の潮汐による海水交換 量)

一日1回潮と一日2回潮に対して $A-P(D)$ 関係式は それぞれ，次式で示すようになる；

（i）一日1回潮の場合は;

$$
D=27516 C_{2} A_{e}
$$

（ii）一日2回潮の場合は；

$$
D=13758 C_{2} A_{e}
$$

上述したように係数 $C_{2}$ は $T_{a m p}$ とheの比の関数なの で，典型的な例を示すと；

$$
\begin{array}{lll}
C_{2}=0.785\left(\frac{T_{\text {amp }}}{h_{e}}\right) & \\
\mathrm{T}_{\text {amp }}=0 & \rightarrow & \mathrm{C}_{2}=0 \text { (no tide) } \\
\mathrm{T}_{\text {amp }}=0.5 \mathrm{~h}_{\mathrm{e}} & \rightarrow & \mathrm{C}_{2}=0.393 \\
\mathrm{~T}_{\text {amp }}=\mathrm{h}_{\mathrm{e}} & \rightarrow & \mathrm{C}_{2}=0.785
\end{array}
$$

\section{ヶース 3；一般型（湖口の水位 $h(t)$ と水平流速} $\underline{u}\left(t_{0}\right)$ の位相差が $\varphi^{\circ}$ の場合の潮汐による海水交換量 $)$

時間 $t=t$ における湖口での水位と水平流速は次式 で表されるとする;

$$
\begin{aligned}
& h(t)=h_{e}+T_{a m p} \sin \left(\frac{2 \pi t}{T_{d}}\right) \\
& u(t)=-u_{e} \sin \left(\frac{2 \pi t}{T_{d}}+\varphi\right)
\end{aligned}
$$

ここで，下げ潮時の海水交換量（放出量） D は， 次式で表される；

$$
\begin{aligned}
& D=\int_{T_{d} / 4}^{3 T_{d} / 4} A(t) \cdot u(t) d t \\
& =-w_{e} \int\left\{h_{e}+T_{\text {anp }} \sin \left(\frac{2 \pi t}{T_{d}}\right)\right\} \cdot u_{e} \sin \left(\frac{2 \pi t}{T_{d}}+\varphi\right) d t \\
& =-W_{e} u_{e} h_{e} \int \sin \left(\frac{2 \pi t}{T_{d}}+\varphi\right) d t-W_{e} u_{e} T_{a m p} \int \sin \left(\frac{2 \pi t}{T_{d}}+\varphi\right) \cdot \sin \left(\frac{2 \pi t}{T_{d}}\right) d t \\
& =-W_{e} u_{e} h_{e} A^{\prime}-W_{e} u_{e} T_{\text {anp }} B^{\prime}
\end{aligned}
$$

上式の $A^{\prime}$ と $B^{\prime}$ 項に関しては，まず以下に示すよ うな変数変換を行った後に, それぞれの值を求める

$$
\begin{aligned}
& X=\frac{2 \pi t}{T_{d}}+\varphi \\
& A^{\prime}=\int_{T_{d} / 4}^{3 T_{d} / 4} \sin \left(\frac{2 \pi t}{T_{d}}+\varphi\right) d t=\int_{\left(\frac{\pi}{2}+\pi\right)}^{\left(\frac{3 \pi}{2}+\varphi\right)}(\sin X) \cdot \frac{T_{d}}{2 \pi} d X \\
& =\frac{T_{d}}{2 \pi}[-\cos X]_{\left(\frac{\pi}{2}+\pi\right)}^{\left(\frac{\pi}{2}+\varphi\right)} \\
& =-\frac{T_{d}}{2 \pi}\left[\cos \left(\frac{3 \pi}{2}+\varphi\right)-\cos \left(\frac{\pi}{2}+\pi\right)\right] \\
& =-\frac{T_{d}}{2 \pi}\left[-\cos \left(\frac{\pi}{2}+\pi\right)-\cos \left(\frac{\pi}{2}+\pi\right)\right] \\
& =\frac{T_{d}}{\pi} \cos \left(\frac{\pi}{2}+\pi\right) \\
& =-\frac{T_{d}}{\pi} \sin \varphi
\end{aligned}
$$

ことにする；

$$
\begin{aligned}
& B^{\prime}=\int \sin \left(\frac{2 \pi t}{T_{d}}+\varphi\right) \cdot \sin \left(\frac{2 \pi t}{T_{d}}\right) d t \\
& =\frac{1}{2} \int\left\{\cos \left(\frac{2 \pi t}{T_{d}}+\varphi-\frac{2 \pi t}{T_{d}}\right)-\cos \left(\frac{2 \pi t}{T_{d}}+\varphi+\frac{2 \pi t}{T_{d}}\right)\right\} d t \\
& =\frac{1}{2} \int\left\{\cos \varphi-\cos \left(\frac{4 \pi t}{T_{d}}+\varphi\right)\right\} d t \\
& =\frac{1}{2}[(\cos \varphi) \cdot t]_{T_{d} / 4}^{3 T_{d} / 4}-\frac{1}{2} \int_{T_{d}}^{3 T_{d} / 4} \cos \left(\frac{4 \pi t}{T_{d}}+\varphi\right) d t \\
& =\frac{1}{4} T_{d} \cos \varphi-\frac{1}{2} \int_{T_{d} / 4}^{3 T_{d} / 4} \cos \left(\frac{4 \pi t}{T_{d}}+\varphi\right) d t
\end{aligned}
$$

ここで，上式の積分に関しても変数変換を行うこ とで, 次式のように解が求まる. 
$X=\frac{4 \pi t}{T_{d}}+\varphi$

$C^{\prime}=\frac{1}{2} \int_{T_{d} / 4}^{3 T_{d} / 4} \cos \left(\frac{4 \pi t}{T_{d}}+\varphi\right) d t$

$=\frac{1}{2} \int_{\pi+\varphi}^{3 \pi+\varphi}(\cos X) \frac{T_{d}}{4 \pi} d x$

$=\frac{1}{2}[\sin X]_{\pi+\varphi}^{3 \pi+\varphi}$

$=\frac{1}{2}[\sin (3 \pi+\varphi)-\sin (\pi+\varphi)]$

$=0$

$\therefore \quad B^{\prime}=\frac{1}{4} T_{d} \cos \varphi$

したがって, 最終的に海水流出量（タイダルプリズ ム）は，次式で表される。

$\therefore D=\int_{T_{d} / 4}^{3 T_{d}} / 4$

$=-W_{e} u_{e} h_{e} \frac{T_{d}}{\pi} \cos \left(\frac{\pi}{2}+\varphi\right)-W_{e} u_{e} T_{a m p}\left(\frac{1}{4}\right) T_{d} \cos (\varphi)$

$=-W_{e} u_{e} T_{d} h_{e}\left\{\frac{1}{\pi} \cos \left(\frac{\pi}{2}+\varphi\right)+\frac{T_{a m p}}{h_{e}}\left(\frac{1}{4}\right) \cos (\varphi)\right\}$

$=-W_{e} u_{e} T_{d} h_{e}\left\{-\frac{1}{\pi} \sin (\varphi)+\frac{T_{a m p}}{h_{e}}\left(\frac{1}{4}\right) \cos (\varphi)\right\}$

$=\left\{\frac{1}{\pi} \sin (\varphi)-\frac{T_{a m p}}{h_{e}}\left(\frac{1}{4}\right) \cos (\varphi)\right\} \cdot T_{d} u_{e} \cdot A_{e}$

$=C_{3} A_{e}$

ここで，新たに係数 $C_{3}$ が導入されたが，ケース 1 から3の総てで，タイダルプリズムPはインレット の断面積 $A$ に依存していることが示された，従って， 本論文中では, 以降, 幾何学的な手法により求めた ある意味で経験的な $A-P$ 関係式を誘導し考察するが, ここまでの誘導で, 幾何学的に求める $A-P$ 関係式の 妥当性が示されたことになる。

\section{（2） $A-P$ データの解析と汎用 $A-P$ 式の誘導}

インレットの安定性に関して，インレットの断面 積 $(A$ で表す)，タイダルプリズム $(P$ で表す)などの既 存データを収集し，データ解析に基づき，世界各地 のインレット断面積 $(A)$ とタイダルプリズム $(P)$ の データからGlobal $A$-P式を導く.さらに自然条件の 場合と人工構造物を用いた場合に分けて本研究で提 案するGlobal $A-P$ 式の特性を考察する. 次に，沿岸 漂砂と潮汐による砂の移動を取り込んだ数值シミュ レーションを用いて，インレットの安定に関する考 察を行う。

図-2の模式図に示すインレット断面積 $(A)$ とタイ ダルプリズム $(P)$ を定量化するために両対数紙上に プロットして回帰直線を求める. なお, タイダルプ
リズムは式(9)および式(10)より定めた.

タイダルプリズム $(\mathrm{P})$ の定義 ;

$$
\mathrm{P}=\Delta \eta \cdot \mathrm{A}_{\mathrm{c}}
$$

$$
\Delta \eta=\eta_{1}-\eta_{2}
$$

ここで， $\eta_{1}$ は大潮平均高潮位， $\eta_{2}$ は大潮平均低潮 位， $A_{C}$ は感潮面積を表す。

インレット断面積 (A) とタイダルプリズム $(\mathrm{P})$ の定 式化に関しては，我が国において近藤 (1972，1990) らのグループにより海跡湖を中心に誘導され，我が 国以外でもM.P.0’Brienなどにより世界で始めてこ の種の研究が行われている. そこで両対数紙上にイ ンレットの断面積 $(A)$ を縦軸, タイダルプリズム $(P)$ を横軸にしてプロットすると線形の傾向が示された ため, この2変量の間に関係式を与え, 本研究で用 いた。 そのインレット断面積 $(A)$ とタイダルプリズ ム $(P)$ のデータを図-4に示す.

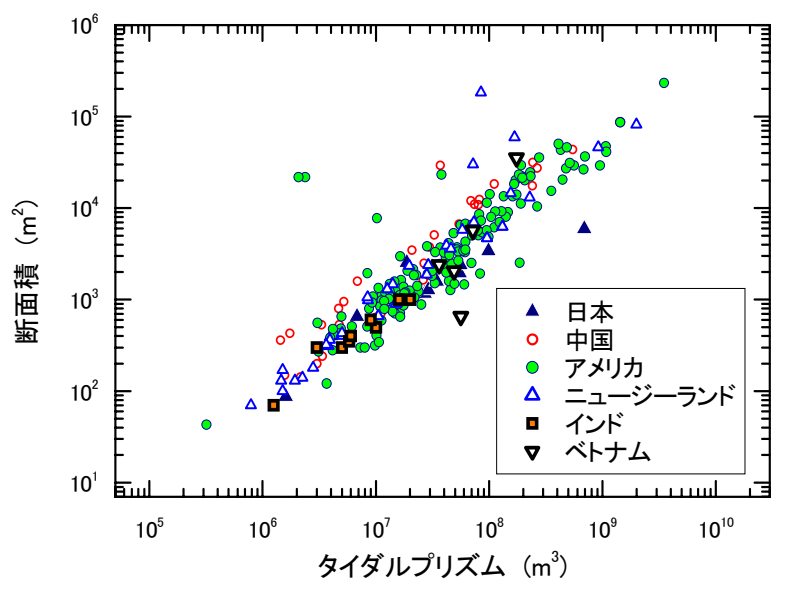

図-4 データ分布図

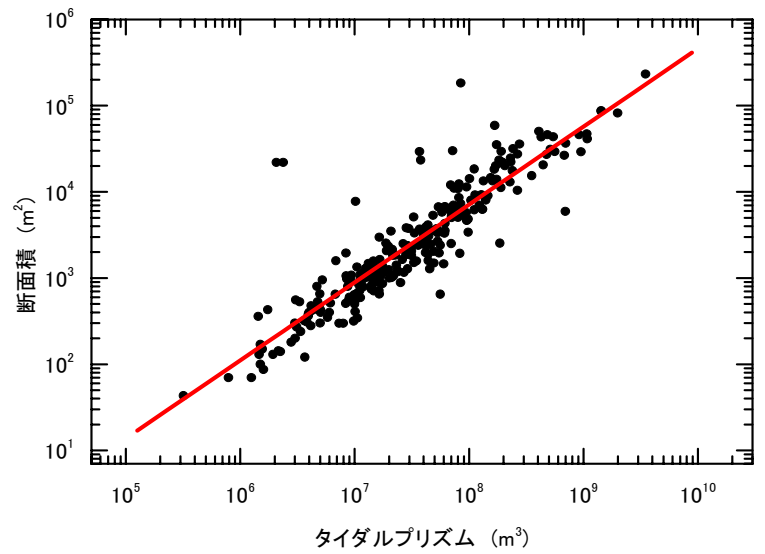

図-5 Global $A-P$ 式

ここで使用したデータは，日本，中国，アメリカ， ニュージーランド，インド，ベトナムの国別に観測 されたものであり，国際海岸工学会議（ICCE）のプ ロシーディングス, 海岸工学論文集, 土木学会論文 集, Journal of Geophysical Research, Shore \& Beachなどの文献から収集した。 なお，本研究で使 
用した分布は右肩上がりの正の相関を示し，イン レット断面積 $(A)$ とタイダルプリズム $(P)$ の関係式は, 最小二乗法を使って求めたものである.また多くの 結果が $R=0.70$ 以上の比較的良好な相関係数を得てい る。世界各地から集められたデータに基づき，今回 データを収集した6力国以外でも利用できるような， 世界中で普遍的に使える式を作成寸ることを試みた。 その結果，図-5に示すような関係を得ることができ， 式(11)で表わすGlobal $A$-P式を提案できた.

$$
A=4.176 \times 10^{-4} P^{0.904}
$$

なお，利用したデータ数は 260 個，相関係数は 0.898である.この式を用いることによってデータ 分布が近似式に対し $60 \%$ 160\%の範囲内に約7割が収 まることを確認した。 また，この 260 個のデータの 中から海岸構造物 (導流堤) の有無の判別ができる 171 個を使って, 海岸構造物の影響が提案した Global A-P式にどのように現れるかを検討した。最 初に同じインレット(浜名湖)で, 海岸構造物ができ る以前の自然状態と構造物 (導流堤)を設けられてか らのデータを(松田, 1983)より調べ，それらが Global $A$-P式とどのような関係があるか考察した. 図-6より浜名湖のデータはGlobal $A-P$ 式に対して バーで示す $50 \%$ ～ $150 \%$ の範囲におさまっていること がわかる。さらに，導流堤建設が始まった1954年以 降について, Global A-P式から計算される断面積は 実際の断面積より過大評価していることがわかる. 図-7に自然状態の場合と導流堤がある場合の $A-P$ 式 を, Global $A-P$ 式と比較して示寸. 自然状態のA-P 式はGlobal $A-P$ 式とほぼ同じ傾きをもっているが， 導流堤がある場合明らかに傾きが小さく, Global A$P$ 式とは $(P, A)=\left(2.383 \times 10^{7}, 1946\right)$ で交差している.

これらの結果から本研究で提案するGlobal $A-P$ 式か ら計算される断面積について, 自然状態の場合は実 際の断面積とほぼ同じで, 導流堤がある場合には $(P, A)=\left(2.383 \times 10^{7}, 1946\right)$ を境にして実際の断面積よ り過大評価することがわかった。

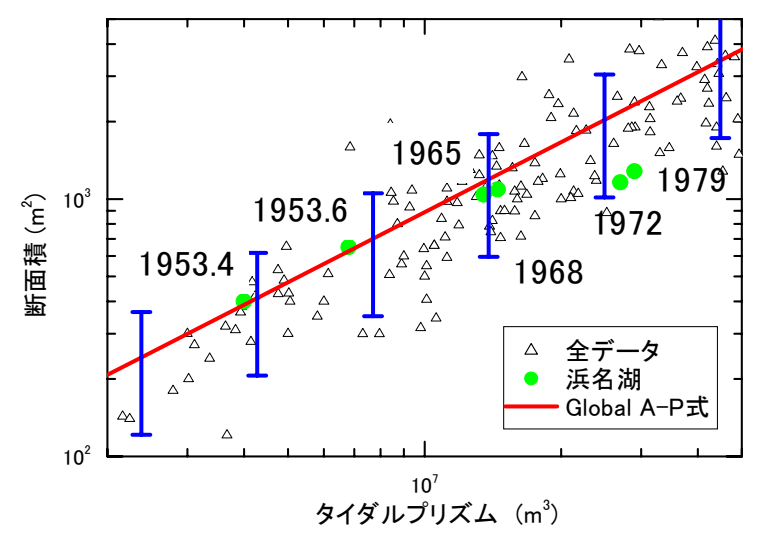

図-6 浜名湖データとGlobal AP式に 対する $60 \%$ 160\%の範囲
次に図-7の分布図よりタイダルプリズム $(P)$ が 7.0 $\times 10^{6} \mathrm{~m}^{3}$ 未満の領域を拡大寸ると, 導流堤有のイン レットが13個に対して自然状態で存在しているイン レットが 3 個となる。なお，導流堤をもったイン レットはタイダルプリズム $(P)$ が $3.10 \times 10^{5} \mathrm{~m}^{3}$ まで 存在している.したがってタイダルプリズム $(P)$ が $7.00 \times 10^{6} \mathrm{~m}^{3}$ 未満に存在するインレットは自然状態 で存在することが稀であり，この範囲におけるイン レットは人工的な構造物を設置しないとインレット が閉塞する可能性が高く, 当面海岸構造物を必要之 する閾 (しきい) 值を $P=3.10 \times 10^{5}\left(\mathrm{~m}^{3}\right) \sim 7.00 \times 10^{6}\left(\mathrm{~m}^{3}\right)$ と定めた.

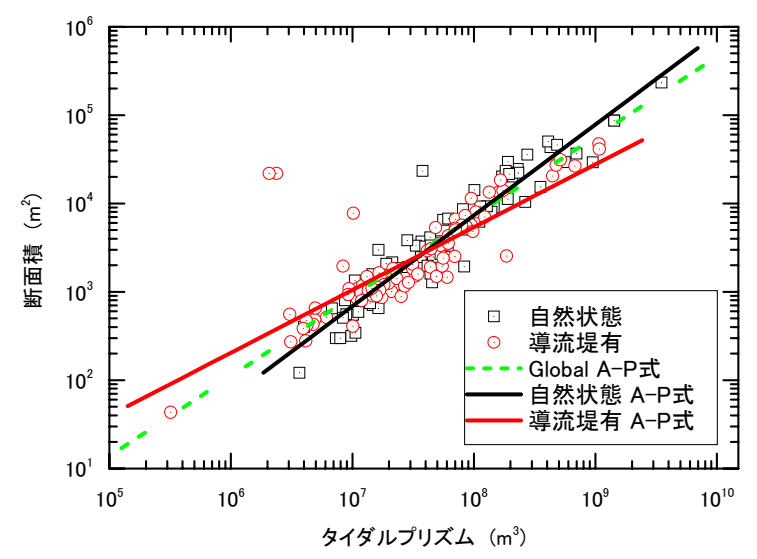

図-7 導流堤有無別 $A-P$ 式とGlobal $A-P$ 式

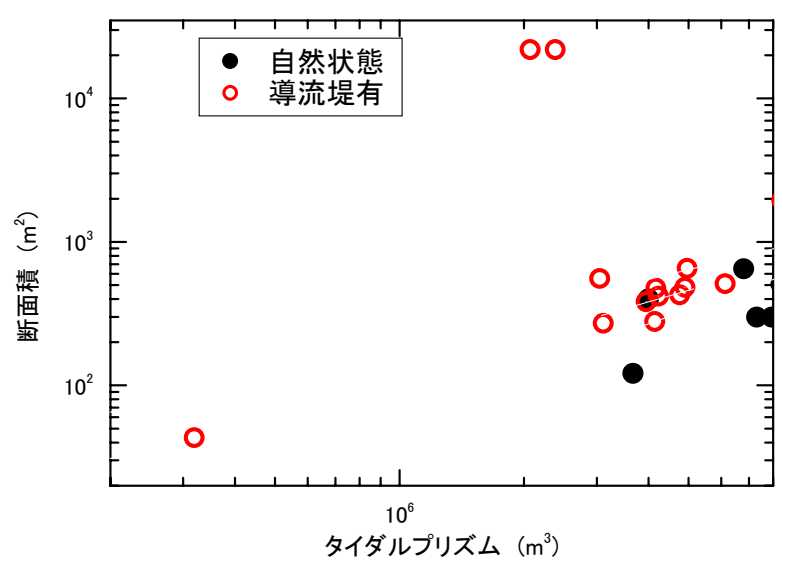

図-8 $\quad P<7.00 \times 10^{6}\left(\mathrm{~m}^{3}\right)$ の拡大図

\section{3. あとがき}

本研究では, 世界中から得られた 260 個のイン レットデータの中から, 海岸構造物 (導流堤) 設置の 有無が判別できる 171 個のデータを使用して, イン レット湖口の断面積とタイダルプリズムの関係に海 岸構造物の影響がどのように現れるかを検討した. その結果, 以下のことが分かった。 
1. 西らによるGlobal $A-P$ 式は自然状態の場合には インレットの断面積をほぼ正当に評価するが，導流 堤がある場合には, タイダルプリズム $P$ が $2.383 \times$ $10^{7}\left(\mathrm{~m}^{3}\right)$ よりも大きい場合, 湖口断面積 $A$ を過大評 価し, タイダルプリズム $P$ が $2.383 \times 10^{7}\left(\mathrm{~m}^{3}\right)$ よりも 小さい場合, 湖口断面積 $A$ を過小評価する傾向があ る.

2. 自然状態で安定しているインレットの $A-P$ に対 して, 導流堤を使用した場合には, 湖口の閉塞を引 き起こす沿岸漂砂を外洋側と内水面側にフラッシュ する海水量の指標であるタイダルプリズムが小さい 条件下でもインレットの安定化（閉塞防止）が実現 できていることがわかった，なお，本データベース の範囲内では, インレットが導流堤で安定化された 場合, タイダルプリズム P が $3.10 \times 10^{5}\left(\mathrm{~m}^{3}\right)$ より 大きければインレットが閉塞していないことが分 かった。

3. 浜名湖では, 導流堤建設が始まった 1954 年以降, 人為的な影響で湖口の断面積とタイダルプリズムが 増加していることが分かる. タイダルプリズムが増 加するということは, より内陸側まで塩水の影響が 及ぶことを意味するので, 生態系への影響が生じた ことが推測される。なお，浜名湖の場合には， Global $A-P$ 式から計算される断面積は, 実際の断 面積を過大評価することがわかった

\section{謝辞}

本研究を行うにあたり，貴重な御意見を頂いた鹿 児島大学水産学部水産生物・海洋学分野海洋環境グ ループの細谷和範博士, 博士課程DE LEON MARIO PERUELO氏に厚く御礼申し上げます.

加えて, 最後まで多大な協力と有益な助言を提供 して下さった同講座の院生繁原俊弘氏，日高公広氏， 学部生の同輩諸氏に厚く御礼申し上げます.

\section{参考文献}

1) 西 隆一郎, Nicholas C. Kraus, 川森 晃; インレット の形状特性に関する基礎的研究, 土木学会論文集の完 全版下投稿用, 2006.

2) 近藤 俶郎; 感潮狭口水路の流速, 内水域潮位および最 大流速水深の一解法,土木学会論文報告集 第 206 pp.4957, 1972.

3) Karniadakis, G.E, Orszag S.A. and Yakhot, V.: Renormalization group theory simulation of transitional and turbulent flow over a backward-facing step, Large Eddy
Simulation of Complex Engineering and Geophysical Flows, Galperin, B. and Orszag, S.A. eds., Cambridge University Press, Cambridge, pp.159-177, 1993.

4) Kondo, H.; Depth of maximum velocity and minimum flow area of tidal entrances, Coastal Engineering in Japan, Vol. 18, pp.167-183, 1975.

5) Kondo, H. ; Design Procedure of artificial channels for tidal entrances, Coastal Engineering in Japan, Vol. 21, pp. 191199, 1978.

6) Kondo, H.; The hydraulics of tidal inlets, Hydraulic Engineering Series, JSCE, B-7, 1979.

7) Kondo, H. ; Flow area prediction of tidal inlet after sea level rise, Proc. of 22nd International Conference on Coastal Engineering, ASCE, pp.3063-3073, 1990.

8) 松田 義弘; 浜名湖の海洋環境-湖口地形変化による湖 内潮汐の経年変化-,沿岸海洋研究ノート第 20 巻,第 2 号, 1983.

9) Zhang Qiaomin ; Analysis of P-A correlationship of tidal inlets along the coasts of South CHINA,Coastal \& Port Engineering in Developing Countries,Vol.1,Edited by Nanjing Hydraulic Research Institute,pp.412-422, 1987.

10)Inman, D. L. and R. W. Harris; Investigation of sedimentation,silting \& dredging requirements, for the United States Navy,Contract NBy-79844, 1966.

11)Bruun, P.; Tidal inlets and littoral drift, Universiteforlaget, Oslo,Norway,p.193, 1966.

12)Per Bruun; Stability of tidal inlets,Elsevier Scientific Publishing Company, Amsterdam, 1978.

13)Jarrett, J. T ; Tidal prism - inlet area relationships, GITI report 3,U.S.Army Engineer Waterways Experiment Station, p55, 1976.

14)Hicks, D.M.and T.M.Hume : Morpholology and size of ebb tidal deltas at natural inlets on open-sea and pocket-bay coasts, North Land, New Zealand. Journal of Coastal Research,vol.12,pp.47-63, 1996.

15)Hume T.M. and C.E. Herdendorf : On the use of empirical stability relationships for characterizing tidal inlets, Journal of Coastal Research, Vol.9,pp.413-422, 1993.

16)O'Brien, M.P: Equilibrium flow areas of tidal inlets on sandy coasts, Proc. of Coastal Engineering, pp.676-686, 1966.

17)Escoffier, F. F ; Hydraulics and stability of tidal inlets, GITI report,U.S. Army Coastal Engineering Research Center, p72, 1977.

18)Trevor colin winton; Long and short term stability of small tidal inlets, A thesis presented to the graduate council of the university of Florida,June, 1979.

19)CEM 1110-2-1100(part II )Hydrodynamics of tidal inlets,chapter6 II -6-1- II -6-59,2002.

20)川森 晃; 北海道オホーツク海沿岸感潮湖沼の湖口海 浜過程の研究, 1993.

21)大木 隆志; 北海道 湖沼と湿原 水辺の散歩道, 2000. 